\title{
NATROSOL SEBAGAI SALAH SATU BAHAN PENGENTAL (THICKENER) PADA PRODUKSI BIOETANOL GEL DARI LIMBAH DAUN TEBU
}

\author{
Rini Kartika Dewi”, Tri Poespowati, Jimmy \\ Jurusan Teknik Kimia Intsitut Teknologi Nasional Malaang, Jl. Bendungan Sigura-gura no 2 Malang, 65145, \\ Indonesia
}

*Rini Kartika Dewi： rinikd@yahoo.co.id

Jimmy : j roring@yahoo.com

Tri Poespowati : poespowati@lecturer.itn.ac.id

\begin{abstract}
Technological advance in energy have a positive impact for the development of energy alternative, which is modification of bioethanol into gel fuels (bioethanol gel / fuel gel). Fuel gels are used as household-fuel or outdoor activities. Some of the advantages of this fuel gel is renewable energy, clean burning (not smoky, odorless), easy ignition and easy distribution. Bioethanol gels consist of ethanol, thickener (generally cellulose derived material) and neutralizer. Natrosol is an Aqualon thickening agent which has a hydroxyethylcellulose active ingredient. The functional groups of $\mathrm{O}-\mathrm{H}$ alcohols (1), C-H alkanes (5) and C-O ester (6) read in the FTIR spectra indicate the presence of hydroxyethylcellulose active ingredients. In addition there is a functional group of $\mathrm{O}-\mathrm{H}$ carboxylic acid (2) and $\mathrm{C}=\mathrm{O}$ (3) which indicates the presence of a mixture of another material which is a carboxylic acid compound in Natrosol. The process of making bioethanol gel is by adding distilled ethanol with $96 \%$ content with the addition of thickener, aquades and triisopropanolamine (as stabilizer). Thickers of natrosol and carbopol with a variation of 0.5; 1.5; 2.0; 2.5 grams, mixed with 31 grams of distilled water and stirred until gel formed, the result is added 75 grams of ethanol and triisopropanolamine. Next, an analysis of the bioethanol gel formed by flame analysis with observed smoke formation, fire color, gas emission and ignition duration
\end{abstract}

Keywords: thickening agent; bioethanol gel; sugarcane leaf waste; natrosol

ABSTRAK

Kemajuan teknologi pada bidang energi memberikan dampak posistif terhadap perkembangan energi alternatif, dimana salah satunya adalah modifikasi bioetanol menjadi bahan bakar gel (bioethanol gel/ fuel gel). Fuel gel banyak digunakan sebagai bahan bakar skala rumah tangga ataupun bahan bakar portabel untuk kegiatan di luar rumah. Beberapa kelebihan dari bioethanol gel antara lain merupakan energi terbarukan, hasil pembakaran bersih (tidak berasap, tidak berbau), penyalaan mudah serta memudahkan dalam distribusi. Bioetanol gel terdiri dari etanol, bahan pengental/ thickener (umumnya material turunan selulosa) dan neutralizer. Natrosol merupakan bahan pengental produksi Aqualon yang memiliki bahan aktif hidroksietilselulosa. Gugus fungsi O-H alkohol (1), C-H alkana (5) dan C-O ester (6) yang terbaca pada spektra FTIR menunjukkan keberadaan bahan aktif hidroksietilselulosa. Selain itu terdapat gugus fungsi O-H asam karboksilat (2) dan $C=O$ (3) yang menunjukkan adanya campuran bahan lain yang merupakan senyawa asam karboksilat di dalam Natrosol. Proses pembuatan bioetanol gel adalah dengan menambahkan etanol hasil distilasi dengan kadar 96\% dengan penambahan pengental (thickener), akuades dan triisopropanolamina (sebagai penstabil). Pengental berupa natrosol dan karbopol dengan variasi 0,5; 1,5; 2.0; 2.5 gram, dicampurkan dengan 31 gram akuades dan diaduk sampai terbentuk gel, hasilnya ditambahkan 75 gram etanol dan triisopropanolamina. Selanjutnya, dilakukan analisis terhadap gel bioetanol yang terbentuk dengan mengamati analisis nyala dengan pengamatan asap yang terbentuk, warna api, emisi gas dan lama penyalaan.

Kata Kunci: bahan pengental; bioetanol gel; limbah daun tebu; natrosol 


\section{PENDAHULUAN}

Secara umum kebutuhan energi berasal dari bahan bakar fosil yang tidak dapat diperbaharui yaitu berasal dari minyak bumi dan batubara.. Akan tetapi selain tidak dapat diperbaharui, hasil pembakaran bahan bakar fosil akan menghasilkan emisi yang dapat mengakibatkan dampak meningkatnya pemanasan global. Selain permasalahan tersebut, jumlah cadangan sumber bahan bakar fosil tidak seimbang dengan meningkatnya kebutuhan energi seiring dengan meningkatnya jumlah populasi, sehingga diperlukan energi pengganti yang dapat diperbaharui dan ramah lingkungan.

Hal tersebut telah menjadikan solusi atau inovasi para peneliti untuk melakukan penelitian tentang bioenergi yang berasal dari biomassa sebagai sumber energi terbarukan. Salah satu daiantaranya bioetanol gel dari limbah daun tebu. Salah satu aplikasi bioetanol yang sedang berkembang saat ini adalah modifikasi menjadi bahan bakar gel (bioethanol gel/ fuel gel).

Fuel gel banyak digunakan sebagai bahan bakar skala rumah tangga atau bahan bakar portabel untuk kegiatan di luar rumah. Beberapa kelebihannya adalah merupakan energi terbarukan, hasil pembakaran bersih (tidak berasap, tidak berbau), , mudah pengemasan dan distribusi serta aman. Bioetanol gel yang didapat dihasilkan dari komposisi etanol, bahan pengental/ thickener (umumnya material turunan selulosa) dan neutralizer. Peneliti-peneliti terdahulu yang telah melakukan penelitian diantaranya membuat bioetanol gel dengan menggunakan etanol dari jagung $(70-80 \%)$, benzoate denatonium (sebagai denaturan nontoksik), homopolimer asam akrilat $(0,3-1,0 \%$, sebagai pengental/ thickening agent), diisopropanolamina $\quad(0,5-1,5 \%$, sebagai penetral) gliserol (4-7\%) dan akuades (15$20 \%$ ). Hasil terbaik didapatkan gel dengan viskositas 45000-85000 cP dan pH 6,9-7,5. Dari fuel gel dngan berat sebesar 500 gram didapatkan waktu pembakaran selama 2-3 jam [1] [Kemudian peneliti berikutnya menggunakan fuel gel sebagai media pembakaran awal bahan bakar padat seperti arang atau briket batubara. Adapun Komposisinya terdiri dari air deionisasi $(23,90 \%)$, polimer poli (asam akrilat) $(0,55 \%)$, etanol $(75 \%)$ dan triisopropanolamina $(0,55 \%)$ [2] Selain itu untuk menyediakan ethanol solid fuel gel digunakan starter (Carbopol EZ3 polymer) sebanyak $0,55 \%$ yang bisa langsung dicampurkan dengan air deionisasi (23,90\%), ethanol (75\%) dan triisopropanolamina $(0,55 \%)$ dan didapatkan waktu penyalaam yang cukup lama yaitu 2,5 jam untuk 200 gram bahan pengental [3] Bahan pengental lain yang dapat digunakan dalam pembuatan Bioetanol gel adalah KatalisNatrium Carboxymethylcellulose ( $\mathrm{Na}$ $\mathrm{CMC}$ ), Asam Stearat dan Bioetanol pada Pembuatan Bioetanol Padat Dari Molases dikatakan bahwa bioetanol padat yang terbaik adalah dengan memakai katalis $\mathrm{Na}$ CMC dan asam stearat yang akan menghasilkan nilai kalor sebesar 6049,633 $\mathrm{kal} / \mathrm{gr}[4]$.

Kemudian dari peneliti diatas dikembangkan dengan menggunakan rasio antara bahan pengental asam stearat dan 
CMC pada bioetanol dari sekam padi didapatkan nilai kalor sebesar 8392,10 $\mathrm{kkal} / \mathrm{kg}$ yang dihasilkan dari berat asam stearat sebesar 4\% [5] dengan menggunakan bahan pengental carbopol 940 pada bioetanol gel dari sekam padi didapatkan nilai kalor sebesar $8522.52 \mathrm{kcal} / \mathrm{kg}$ dengan lama pembakaran selama 23 menit 31 detik [6].

Terdapat juga peneliti yang menggunakan bahan pengental dari Carboxymethycellulose (CMC) menghasilkan nilai kalor $11.751 \mathrm{~J} / \mathrm{gr}$ dan viskositas sebesar 17434 cP yang didapatkan pada pembakaran gel etanol dengan konsentrasi etanol $90 \%$ dan penambahan CMC 1.8 gram serta residu pembakaran $29.44 \%$ [7].

Nilai kalor yang dihasilkan dari [4], [5] dan [6] bersimpangan dengan pendapat bahwa untuk bioetanol gel yang digunakan sebagai bahan bakar secara umum memiliki nilai Lower Heating Value (LHV) yang rendah [8].

Bahan pengental carbopol 940 tidak hanya digunakan sebagai bahan pengental untuk bahan bakar tetapi bisa juga digunakan untuk bahan pengental pada minyak atsiri seperti pada produk dedodoran [9] dan juga Pemanfaatan bahan alami sebagai zat aktif obat sekarang kembali digalakkan dan mulai dikembangkan. Teknologi yang ada dimanfaatkan guna menghasilkan sediaan farmasi yang lebih aman dan efektif dalam proses pengobatan yaitu dengan kombinasi bahan pengental Karbopol, gelatin dan CMC. [10]

Dari beberapa penelitian tentang bahan bakar gel dapat dikatakan bahwa komponen kunci yang berpengaruh dalam pembentukan bioetanol gel adalah thickening agent (bahan pengental). Pada penelitian ini peneliti mencoba menggunakan bahan pengental lain yaitu natrosol. Dimana dari produk bioetanol gel yang dihasilkan nantinya akan dialakukan analisa untuk mengetahui karakteristik dari pada bahan bakar gel tersebut.

Produk bioetanol Gel terbaik dipertimbangkan dari indikator waktu pembakaran, tekstur gel, daya alir rendah, nyala api biru, tidak berasap dan stabilitas pembakaran baik (menyala sampai habis) serta ada tidaknya emisi gas yang dihasilkan.

\section{METODE PENELITIAN}

\section{Instrumentasi}

Fourier Transform Infrared Spectroscopy (FTIR) merupakan metode pengujian gugus fungsi organik yang terkandung pada suatu bahan. Pengujian FTIR dilakukan pada bahan pengental natrosol untuk validasi keberadaan bahan aktif yang terkandung dan gugus fungsional mayoritas yang ada..

\section{Prosedur}

\section{Pembuatan Bioetanol Gel}

Bioetanol Gel dibuat dari bioetanol hasil distilasi dengan kadar 96\% dari limbah daun tebu dengan penambahan pengental (thickener), dan akuades. Pengental berupa karbopol, natrosol dengan variasi 0,$5 ; 1,00$; 1,$50 ; 2.0 ; 2.5$ gram, dicampurkan dengan 25,5 gram akuades dan diaduk sampai terbentuk gel (maksimal selama 1 jam), hasilnya ditambahkan 50 gram bioetanol. Selanjutnya, melakukan analisis nyala dengan pengamatan asap yang terbentuk, warna api, kestabilan nyala dan lama penyalaan serta emisi gas yang dihasilkan 
dengan menggunakan peralatan gas analyser.

\section{HASIL DAN PEMBAHASAN}

Fourier Transform Infrared Spectroscopy (FTIR)

Fourier Transform Infrared Spectroscopy (FTIR) merupakan metode pengujian gugus fungsi organik yang terkandung pada suatu bahan. Pengujian FTIR dilakukan pada bahan pengental natrosol untuk validasi keberadaan bahan aktif yang terkandung dan gugus fungsional mayoritas yang ada. Spektra FTIR untuk bahan tersebut ditunjukkan pada Gambar di bawah ini.

Natrosol merupakan bahan pengental produksi Aqualon yang memiliki bahan aktif hidroksietilselulosa. Gugus fungsi O-H alkohol (1), C-H alkana (5) dan C-O ester (6) yang terbaca pada spektra FTIR menunjukkan keberadaan bahan aktif hidroksietilselulosa. Selain itu terdapat gugus fungsi $\mathrm{O}-\mathrm{H}$ asam karboksilat (2) dan $\mathrm{C}=\mathrm{O} \quad$ (3) yang menunjukkan adanya campuran bahan lain yang merupakan senyawa asam karboksilat di dalam Natrosol

Pada awal proses peneliti melakukan proses pengentalan dengan menggunakan natrosol saja dan ternyata hasil yang didapatkan tidak terbentuk gel dengan baik. Sehingga dalam penelitian ini peneliti mengkombinasi bahan pengental natrosol dan carbopol. Carbopol merupakan bahan pengental produksi Lubrizol yang memiliki bahan aktif asam poliakrilat.
Dari Spektra FTIR Carbopol Keberadaan gugus fungsi $\mathrm{O}-\mathrm{H}$ asam karboksilat (2), C=O (3), C-H alkana (5) dan C-O asam karboksilat (6) menunjukkan keberadaan bahan aktif asam akrilat.

\section{Analisa Lama Waktu Penyalaan}

Salah satu karakteristik bioetanol gel yang dilakukan adalah analisa lama waktu penyalaan. Dimana dalam analisa tersebut sampel kami ambil sebanyak 20 gram yang diletakkan dalam cawan kemudian dibakar sampai sampel habis. Adapun pada pembakaran bioetanol gel tidak dihasilkan asap sama sekali.

Hasil yang didapatkan untuk analisa nyala api dapat dilihat pada tabel di bawah ini .

Tabel 1. Hasil Variasi Pengental Natrosol Terhadap Lama Pembakaran

\begin{tabular}{|c|c|c|c|}
\hline \multirow[t]{2}{*}{ No } & \multicolumn{2}{|c|}{ Komposisi } & \multirow{2}{*}{$\begin{array}{c}\text { Lama } \\
\text { Waktu } \\
\text { (menit) }\end{array}$} \\
\hline & $\begin{array}{c}\text { Carbopol } \\
\text { (gram) }\end{array}$ & $\begin{array}{c}\text { Natrosol } \\
\text { (gram) }\end{array}$ & \\
\hline \multirow[t]{5}{*}{1} & 0.5 & 0,5 & 11,75 \\
\hline & 1.0 & & 22,00 \\
\hline & 1.5 & & 30,60 \\
\hline & 2.0 & & 30,95 \\
\hline & 2.5 & & 29,45 \\
\hline \multirow[t]{5}{*}{2} & 0.5 & 1,5 & 20,40 \\
\hline & 1.0 & & 22,20 \\
\hline & 1.5 & & 25,35 \\
\hline & 2.0 & & 25,40 \\
\hline & 2.5 & & 25,40 \\
\hline \multirow[t]{5}{*}{3} & 0.5 & 2,5 & 25,55 \\
\hline & 1.0 & & 26,15 \\
\hline & 1.5 & & 26,85 \\
\hline & 2.0 & & 22,80 \\
\hline & 2.5 & & 22,60 \\
\hline
\end{tabular}




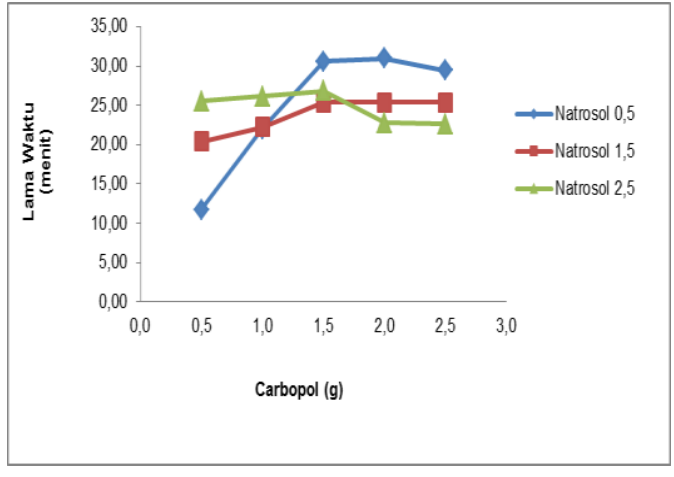

Gambar 4. Hubungan antara massa natrosolcarbopol Terhadap Lama Waktu Penyalaan

Penambahan massa carbopol dan natrosol menunjukkan pengaruh kecenderungan pada kenaikan waktu penyaalaan bioetanol gel dimana kenaikan terjadi pada penambahan carbopol $(1,5-2)$ gram. Akan tetapi apabila massa carbopol dan natrosol berlebihan akan mempengaruhi viskositas atau semakin kentalnya bioetanol gel yang dihasilkan hal ini menyebabkan pengurangan kualitas dari penyalaan pada waktu pembakaran. Waktu penyalaan terlama yang dihasilkan adalah 30,95 menit. Pada rasio bahan pengental antara carbopol dan natrosol : 2,$0 ; 0,5$

\section{Analisa Warna Nyala Api}

Dalam proses pembakaran, bioetanol gel menghasilkan warna api dari gel selama pembakaran. Pada proses pembakaran api yang baik adalah berwarna biru, akan tetapi jika dihasilkan warna merah hal ini disebabkan karena proses pewmbakaran yang tidak sempurna. Pada analisa ini bioetanol gel yang diambil adalah sebanyak $5 \mathrm{gr}$, kemudian dimasukkan dalam cawan porselen. Kemudian bioetanol Gel dibakar dan diamati warna nyalanya.
Dari hasil pembakaran gel bioetanol didapatkan data sebagai berikut :

Tabel 2. Hasil Variasi Pengental Natrosol Terhadap Nyala Api

\begin{tabular}{|c|c|c|c|}
\hline \multirow[t]{2}{*}{ No } & \multicolumn{2}{|c|}{ Komposisi } & \multirow[t]{2}{*}{ Warna Nyala Api } \\
\hline & $\begin{array}{c}\text { Carbopol } \\
\text { (gram) }\end{array}$ & $\begin{array}{c}\text { Natrosol } \\
\text { (gram) }\end{array}$ & \\
\hline \multirow[t]{5}{*}{1} & 0.5 & 0,5 & Biru Kemerahan \\
\hline & 1.0 & & Merah Kebiruan \\
\hline & 1.5 & & Merah Kebiruan \\
\hline & 2.0 & & Merah Kebiruan \\
\hline & 2.5 & & Merah Kebiruan \\
\hline \multirow[t]{5}{*}{2} & 0.5 & 1,5 & Biru Kemerahan \\
\hline & 1.0 & & Merah Kebiruan \\
\hline & 1.5 & & Merah Kebiruan \\
\hline & 2.0 & & Merah Kebiruan \\
\hline & 2.5 & & Biru Kemerahan \\
\hline \multirow[t]{5}{*}{3} & 0.5 & 2,5 & Merah Kebiruan \\
\hline & 1.0 & & Merah Kebiruan \\
\hline & 1.5 & & Merah Kebiruan \\
\hline & 2.0 & & Merah Kebiruan \\
\hline & 2.5 & & Merah Kebiruan \\
\hline
\end{tabular}

Terlihat dari hasil ternyata nyala apinya masih banyak yang berwarna merah, hal ini disebabkan karena semakin banyak bahan pengental yang ditambahkan maka rasio antara bahan pengental dengan julmlah oksigen yang ada tidak sesuai sehingga menghasilkan pembakaran yang tidak sempurna.

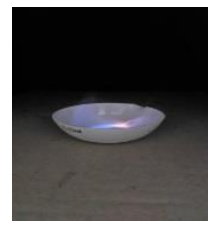

Natrosol $0,5 \mathrm{~g}$

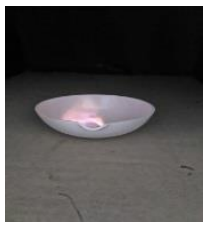

Natrosol 1,5 g

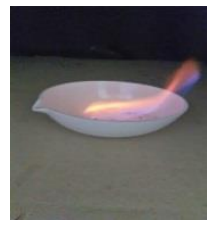

Natrosol 2,5 g
Gambar 5. Analisa Nyala Api 


\section{Analisa Emisi Gas}

Emisi gas merupakan analisa yang bertujuan untuk mengetahui komposisi gas hasil pembakaran bersifat polusi ataukah ramah lingkungan. Analisa Emisi dilakukan dengan uji menggunakan peralatan yang disebut Stargas Gas Analyzer. Dari hasil penelitian terlihat gas $\mathrm{CO}$ untuk semua bahan pengental sangat tinggi dibandingkan yang lain. Terbentuknya gas CO dikarenakan reaksi pembakaran tidak berjalan sempurna. Penyebabnya adalah bahan bioetanol gel masih terdapat bahanbahan impuritis yang terkandung sehingga mempengaruhi hasil analisa emisi gas.

Tabel 3. Hasil Variasi Pengental Natrosol Terhadap Emisi Gas

\begin{tabular}{cccccc}
\hline Sampel & $\begin{array}{c}\mathrm{CO} \\
(\mathrm{ppm})\end{array}$ & $\begin{array}{c}\mathrm{NOx} \\
(\mathrm{ppm})\end{array}$ & $\begin{array}{c}\mathrm{SO}_{2} \\
(\mathrm{ppm})\end{array}$ & $\begin{array}{c}\mathrm{H}_{2} \mathrm{~S} \\
(\mathrm{ppm})\end{array}$ \\
\hline Natrosol & 0.5 & 469 & 17 & 2 & 22
\end{tabular}

(1)

\begin{tabular}{lcccc}
\hline Natrosol 0.5 (2) & 469 & 8 & 0 & 15 \\
\hline Natrosol 0.5 (3) & 476 & 6 & 2 & 12 \\
\hline Natrosol 0.5 (4) & 473 & 10 & 5 & 9 \\
\hline Natrosol 0.5 (5) & 462 & 22 & 2 & 15 \\
\hline Natrosol 1.5 (1) & 470 & 7 & 0 & 9 \\
\hline Natrosol 1.5 (2) & 467 & 5 & 0 & 9 \\
\hline Natrosol 1.5 (3) & 468 & 8 & 0 & 12 \\
\hline Natrosol 1.5 (4) & 468 & 17 & 2 & 13 \\
\hline Natrosol 1.5 (5) & 468 & 16 & 15 & 10 \\
\hline Natrosol 2.5 (1) & 468 & 16 & 8 & 8 \\
\hline Natrosol 2.5 (2) & 465 & 32 & 10 & 12 \\
\hline Natrosol 2.5 (3) & 465 & 29 & 15 & 13 \\
\hline Natrosol 2.5 (4) & 465 & 53 & 14 & 17 \\
\hline Natrosol 2.5 (5) & 463 & 91 & 7 & 24 \\
\hline
\end{tabular}

\section{KESIMPULAN}

Dari hasil penelitian yang telah dilaksanakan didapatkan bahwa jika dilihat dari lama penyalaan yang paling optimal adalah perbandingan massa carbopol dan natrosol pada 1,5 : 2 dengan lama waktu 30,95 menit begitu juga untuk warna penyalaan hampir keseluruhan warna apinya sama yaitu awal merah kemudian biru sampai bioetanolnya habis. Sedangkan untuk emisi gas yang paling optimal adalah yang menghasilkan emisi paling kecil adalah perbandingan carbopol : natrosol 1:1,5 adapun hasil NOx : 5 ppm, SO2 :0 da H2S : 9 ppm. Serta gas CO : 467 ppm .Jika dilihat dari keseluruhan emisi gas kecuali gas $\mathrm{CO}$ untuk semua sampel bioetanol gel yang dihasilkan masih masuk standar.[12].

\section{UCAPAN TERIMAKASIH}

Kami mengucapkan banyak terima kasih atas Ditlitabmas Ditjen Dikti yang telah memberikan dana penelitian dalam Pelaksanaan Program Penelitian Desentralisasi Hibah Penelitian Produk Terapan.

\section{DAFTAR PUSTAKA}

[1] Dorries, D.E., Heaberlin, K., Kuhn, J., Riley, R., Miller, R.E. Chafing Dish Fuel, US Patent No. US 2010/0186286 A1, 2010.

[2] Kort-Kamp, M Fuel Gel, US Patent No. US 2013/0104446 A1, 2013.

[3] Lubrizol. Ethanol Solid Fuel Gel/Fire Starter, H-MC0006, Lubrizol Advanced Materials, Inc, 2006

[4] Akhiroh Islam Nur Jannatul, dkk, , Nisbah Katalis Natrium Carboxymethylcellulose ( $\mathrm{Na} \mathrm{CMC}$ ), Asam Stearat Dan Bioetanol Terhadap karakteristik Pembuatan Bioetanol Padat Dari Molasess, JTM volume 03 Nomoer 03 Tahun 2015

[5] Rini Kartika Dewi, Boediyanto, Optimalisasi Sekam Padi Sebagai Alternatif Bahan Bakar Gel Yang Ramah Lingkungan, Prosiding Seminar Nasional Kimia dan Pembelajarannya, ISBN : 987-602-095112-6, 17 September 2016

[6] Rini Kartika Dewi, Boediyanto, Renewable Energy From Rice Husk, International Journal of ChemTech Research, ISSN :0974-4290, Vol.10 No. 44, pp 457-463, 2017

[7] Almira Nugroho, Fajar Restuhadi dan Evy Rossi, Pembuatan Gel Etanol Dengan Menggunakan Bahan Pengental Corboxymethycellulose (CMC), Jom Faperta, vol.3 no.1, 1 Februari 2016.

[8] Lloyd, P.J.D. dan Vissagie, E.M., A Comparison of Gel Fuels With Alternative Cooking Fuels. Journal of Energy in Southern Africa, Vol 18 No. 3. August 2007. 
[9] Taty Rusliati Rusli, Zulhipri, Pengaruh Mutu Pengental Terhadap Mutu Minyak Atsiri Kulit Buah Jeruk Purut (Citrus hystrix Dc) Dalam sediaan Deodoran, Jurnal IImu Kefarmasian Indonesia, ISSN 1693-1831, vol.14 no.1, April 2016

[10] Hosea Jaya Edy, Marchaban, Subagus Wahyuono dan Agung Endro Nugroho, Formulasi Dan Uji Sterilisasi Hidrogel Herbal Ekstrak Etanol Daun Tagetes erecta L, Jurnal IImiah farmasi - UNSRAT, vol. 5 no. 2, ISSN $2302-2493$, Mei 2016

[11] Aqualon, Natrosol Hydroxyethylcellulose A Nonionic Water-Solub le Polymer Physical and Chemical Properties, Hercules Incorporated, 1999.

[12] Peraturan Pemerintah Republik Indonesia Nomor 41 Tahun 1999 Tentang Pengendalian Pencemaran Udara 